\title{
Inflation and Interest Rate Interaction: An Analysis of the Validity of the Gibson Paradox in Turkey
}

\author{
Dr. Mustafa Göktuğ Kaya (Ministry of Treasury and Finance, Turkey) \\ Ph.D. Candidate Yiğit Yıldız (Ministry of Treasury and Finance, Turkey)
}

\begin{abstract}
The purpose of this study is to analyze whether the Gibson paradox is valid in Turkey. As it is known, inflation is an important issue that should be emphasized by policy makers. For this reason, inflation has been the subject of many studies in economics. One of the highlights of these studies is the Gibson paradox. The same directional and statistically strong relationship between the general level of prices (inflation) and interest rates in the long run is expressed as the Gibson Paradox in economics literature. The Gibson's paradox, first put forward by John Maynard Keynes, is called a paradox because the relationship in question contradicts the propositions of Classical Economic Thought. In this study, the interaction between the consumer price index (CPI) and 12 months term TL deposit interest rates in Turkey was analyzed for the period 2003:QI-2021:QI, using the Johansen Co-integration Test approach. According to the analysis results, inflation in the Turkish economy has an undeniable positive effect on interest rates. In other words, Gibson paradox is valid in Turkey in the period under consideration.
\end{abstract}

The full text of this paper presented at the International Conference on Eurasian Economies 2021 was submitted to an academic journal for publication and therefore has been excluded from the conference proceedings. 